\title{
Effects of bone marrow mesenchymal stem cells on the cardiac function and immune system of mice with endotoxemia
}

\author{
YUANFAN WU, JING ZHOU, LIQING BI, MIN HUANG, YI HAN, \\ QIAN ZHANG, DONGMEI ZHU and SUMING ZHOU
}

Department of Geriatrics, The First Affiliated Hospital of Nanjing Medical University, Nanjing, Jiangsu 210029, P.R. China

Received March 25, 2015; Accepted December 22, 2015

DOI: $10.3892 / \mathrm{mmr} .2016 .5151$

\begin{abstract}
The present study aimed to investigate the effects of bone marrow mesenchymal stem cells (MSCs) on the cardiac function and immune system of mice with endotoxemia. The mice were divided into the following groups: Control group, endotoxemia group, lipopolysaccharide (LPS) treatment group, LPS and MSC treatment group (LPS + MSC group) and MSC group. Following treatment with LPS, the cardiac function of the mice was examined at after 2, 6 and $24 \mathrm{~h}$, and on day 7. An enzyme-linked immunofluorescent assay was used to analyze the serum and the levels of cytokines in the myocardium, and western blotting was used to investigate any changes in the levels of signaling proteins associated with the myocardium. A 3-(4,5-dimethyl-2-thiazolyl)-2,5-diphenyl-2H-tetrazolium bromide assay was used to investigate the growth rate of the splenic cells at after $24 \mathrm{~h}$ and on day 7, and the humoral immune function and phagocytosis of the macrophages in the mice were also examined. The cardiac function of the mice with endotoxemia declined, although this impairment was circumvented following treatment with MSCs. The levels of interleukin (IL)-1 $\beta$, IL-6, tumor necrosis factor- $\alpha$ and IL-10 in the serum and the myocardium increased following stimulation by LPS, although these declined as a result of MSC treatment. The expression levels of Toll-like receptor 4, p65-nuclear factor- $\kappa \mathrm{B}$ and phosphorylated p38 in the mouse myocardium were enhanced following stimulation by LPS, which subsequently decreased as a result of MSC treatment. Compared with the control group, the growth rate of the splenic cells, humoral immune function and the level of phagocytosis of macrophages were all increased, although these parameters declined following treatment with MSCs. Taken together, the present study revealed that the
\end{abstract}

Correspondence to: Dr Suming Zhou, Department of Geriatrics, The First Affiliated Hospital of Nanjing Medical University, 300 Guangzhou Road, Nanjing, Jiangsu 210029, P.R. China

E-mail: doccomp@163.com

Key words: bone marrow mesenchymal stem cells, endotoxemia, cardiac function, immune function
MSCs inhibited the inflammatory reaction in the mice with endotoxemia, and improved cardiac function. By contrast, the cellular and humoral immunity were depressed, and phagocytosis of the macrophages, which were enhanced following simulation with LPS, were decreased following treatment with MSCs. However, no overexpression of the anti-inflammatory factor, IL-10, was observed. The present study hypothesized that MSCs exert a bifunctional role in endotoxemia, by inhibiting inflammatory factors, including IL-1 and IL-6, and inhibiting the compensatory expression of IL-10 following LPS stimulation. This avoids the possibility of excessive inhibition of immunological function, as this results in immunosuppression, and a higher ratio of IL-10 to TNF- $\alpha$ is indicative of a poor prognosis in patients with sepsis.

\section{Introduction}

Sepsis poses a serious threat to the life of patients, resulting in multiple organ failure syndrome. Treatment options at present include surgery, antibiotics and other supportive treatments, however, the therapeutic options available remain unsatisfactory in terms of efficacy, with a mortality rate of $\sim 30 \%$ (1). In the United States, $\sim 250,000$ patients succumb to sepsis-associated mortality every year (2). Sepsis predominantly results in organic dysfunction due to the LPS, which is produced by bacteria and interacts with the human inherent immune system, resulting in its dysfunction $(3,4)$ and leading to activation of the inherent immune system, the inhibition of adaptive immunity, mitochondrial dysfunction and hypermetabolism accompanied by insulin resistance. Furthermore, the enhancement in capillary permeability leads to tissue edema, which eventually results in the dysfunction of tissue organs (4). One of the clinical manifestation of sepsis is the impairment and insufficiency of cardiac function. A previous study indicated that, among 235 patients who succumbed to sepsis or septic shock-associated mortality, those exhibiting cardiovascular system failure accounted for $35.3 \%$ (5). As the inflammatory reaction is important in sepsis, previous studies have attempted to use monoclonal antibodies raised against specific inflammatory factor receptors to inhibit the inflammatory reaction $(2,6)$. However, sepsis results from interactions among various inflammatory factors and, as a result, treatments based on monoclonal antibodies lose 
their therapeutic potential due to the targeting of a single receptor (2).

As the inflammatory reaction is closely associated with immunological abnormalities in sepsis, effective treatments, which are able inhibit excessive inflammatory reactions and regulate immunological abnormality are of interest. Previous studies have demonstrated that mesenchymal stem cells (MSCs) are able to regulate the immune system, and MSCs have been used to treat a range of conditions, including acute lung injury, inflammatory bowel disease, graft versus-host reactions and ischemic heart disease $(7,8)$. Previous attempts have been made to treat sepsis using MSCs, and MSCs have been successfully used in animals to inhibit the systemic inflammation reaction through interleukin (IL)-10, and thereby relieve the functional impairment, which is associated with sepsis and endotoxemia (7-11).

MSCs have also elicited improved therapeutic effects on the cardiac insufficiency associated with sepsis, accompanied by a decreased expression of inflammatory factors, including tumor necrosis factor- $\alpha$ (TNF- $\alpha$ ) and IL-1 (11). However, at present, the treatment for sepsis using MSCs is focused more on the inhibition of the excessive inflammatory reaction caused by sepsis, and the effect of MSCs on the immune system remain to be fully elucidated. As lipopolysaccharide (LPS) is the predominant compound promoting the involvement of Gram-negative bacteria in sepsis, and the severity of sepsis is correlated with the concentration of LPS in the circulatory system $(12,13)$, LPS is commonly injected into an animal model in order to simulate sepsis.

In the present study, MSCs were used to treat mice with endotoxemia, with the aim to observe the effects of the MSCs on cardiac function, and on the levels of cytokines in the serum and myocardium of mice with endotoxemia. In addition, the effects of MSCs on the immune system were investigated, in order to assist in the development of novel therapies using MSCs for treating sepsis.

\section{Materials and methods}

Bone marrow MSCs. All the animal experiments in the present study were performed in accordance with the Experimental Animal Management Regulations in Nanjing Medical University (Nanjing, China). The present study was approved by the ethics committee of the First Affiliated Hospital of Nanjing Medical University (Nanjing, China). A total of 80 C57 BL/6 male mice (aged 8-10 weeks, weighing $\sim 25 \mathrm{~g}$, $12 \mathrm{~h}$ light/dark cycle), maintained at $24^{\circ} \mathrm{C}$ and $50 \%$ humidity were purchased from the Animal Core Facility in Nanjing Medical University. The mice were sacrificed by cervical vertebra dislocation, and soaked in $75 \%$ alcohol for sterilization purposes for $15 \mathrm{~min}$. The bilateral shafts of the femurs were extracted under sterile conditions. The cavitas medullaris was washed with $10 \mathrm{ml}$ phosphate-buffered saline (PBS) using a sterile $5 \mathrm{ml}$ syringe, prior to the disposal of the femoral shafts. The washed bone marrow was mixed by lashing and stirring, following which the marrow was centrifuged at $750 \mathrm{x} \mathrm{g}$ for $5 \mathrm{~min}$ at $20^{\circ} \mathrm{C}$, and the supernatant was discarded. The remainder was resuspended in high-glucose Dulbecco's modified Eagle's medium (DMEM; GE Healthcare Life Sciences, Logan, UT, USA) containing 10\% Gibco fetal bovine serum (FBS; Thermo Fisher Scientific, Inc., Waltham, MA, USA) and was subsequently inoculated in a Petri-dish (10 cm diameter) at $37^{\circ} \mathrm{C}$ in an incubator containing $15 \% \mathrm{CO}_{2}$. Following incubation for 4 days, the medium was replaced for the first time with high-glucose DMEM containing 10\% FBS, following which the medium was replaced every day until $80 \%$ of the cells were entering cell fusion at a 1:2 passage. The third generation cells were used.

Treatment of mice with endotoxemia using MSCs. A total of 80 C57 BL/6 male mice (aged 8-10 weeks, weighing 25 g) were selected for the present study. The mice were provided with free access to food (grain feed) and water, and were housed at a temperature of $24^{\circ} \mathrm{C}$ and $50 \%$ humidity. The following four groups of mice were established: Control; lipopolysaccharide (LPS) treatment; LPS and MSC treatment (LPS + MSC group) and MSC treatment group, with 20 mice in each group. LPS (Sigma-Aldrich, St. Louis, MO, USA) was used at a concentration of $0.5 \mathrm{mg} / \mathrm{ml}$, and the concentration of MSCs used was $2 \times 10^{6} / \mathrm{ml}$. In the control group, $0.5 \mathrm{ml}$ phosphate-buffered saline (PBS) was administered through peritoneal injection and, after $1 \mathrm{~h}, 0.5 \mathrm{ml}$ PBS was administered via vena caudalis injection. In the LPS group, $10 \mathrm{mg} / \mathrm{kg}$ LPS was administered via peritoneal injection and, $1 \mathrm{~h}$ later, $0.5 \mathrm{ml}$ phosphate-buffered saline (PBS) was administered via vena caudalis injection. In the LPS + MSC group, $10 \mathrm{mg} / \mathrm{kg}$ LPS was administered via peritoneal injection and, $1 \mathrm{~h}$ later, $10^{6}$ bone marrow MSCs were administered via vena caudalis injection. In the MSC group, $0.5 \mathrm{ml}$ PBS was administered via peritoneal injection and, $1 \mathrm{~h}$ later, $10^{6}$ bone marrow MSCs were administered via vena caudalis injection. No mice died throughout the course of the experiment all were sacrificed by cervical vertebra dislocation. The cardiac functions of the mice were investigated using a two-dimensional echocardiogram (Vevo 2100; VisualSonics, Inc., Toronto, Canada) 2, 6 and 24 h, and 7 days following LPS injection. Subsequently, five mice in each group were sacrificed in order to examine the associated tissues.

Determination of the serum and the myocardial inflammatory factor. A total of $500 \mu \mathrm{l}$ of blood was collected from each mouse and maintained at physiological temperature. Following incubation for $1 \mathrm{~h}$, the blood was centrifuged at 2,000 x g for $10 \mathrm{~min}$ to obtain the serum. Myocardial tissues were homogenized in 10 weight/volume of sodium chloride on ice and then centrifuged at $10,000 \times \mathrm{g}$ for $15 \mathrm{~min}$ at $4^{\circ} \mathrm{C}$. The supernatants were collected for IL- $1 \beta$, IL- 6 , TNF- $\alpha$ and IL-10 assays with enzyme-linked immunosorbent assay (ELISA) kits. An ELISA assay kit was purchased from R\&D Systems, Inc. (Minneapolis, USA). Aliquots $(50 \mu \mathrm{l})$ of the standard, control or sample solution mixed with $50 \mu \mathrm{l}$ assay dilutant were added to each well, and the mixtures were incubated at room temperature for $2 \mathrm{~h}$. Following the removal of unbound material by washing five times, $100 \mu 1$ conjugate was added to each well and incubated at room temperature for $2 \mathrm{~h}$. Following rinsing, $100 \mu \mathrm{l}$ substrate solution was added and incubated at room temperature in the dark for $30 \mathrm{~min}$, the reaction was terminated by adding $100 \mu \mathrm{l}$ stop solution to each well, and the optical density was read at $450 \mathrm{~nm}$ within $30 \mathrm{~min}$ using an SH-1000 microplate reader (Corona Electric Co., Ltd, Hitachinaka, Japan). 
Determination of myocardial signal pathway proteins. A total of $0.1 \mathrm{~g}$ of myocardial tissue was obtained, to which $1 \mathrm{ml}$ lysate and $10 \mu \mathrm{l}$ phenylmethyl sulfonylfluoride solution (Sigma-Aldrich) were added prior to homogenization. The homogenate was centrifuged at $12,000 \times \mathrm{g}$ for $20 \mathrm{~min}(4 \mu \mathrm{l})$, and the supernatant was collected to measure the concentration of protein using the Bradford protein assay method (Jiancheng Biotech, Nanjing, China), with bovine serum albumin as a standard (diluted to a concentration of $5 \mathrm{mg} / \mathrm{ml}$ ). The proteins were separated using sodium dodecyl sulfate (SDS)-PAGE (5 $\mu \mathrm{g} / \mu \mathrm{l}$ per well; 12\%; Bio-Rad Laboratories, Inc., Hercules, CA, USA), and were electrotransferred (300 mA) onto a polyvinylidene fluoride (PVDF) membrane (EMD Millipore, Billerica, MA, USA). The myocardial proteins were sealed off using $5 \%$ defatted milk powder as the blocking agent for $2 \mathrm{~h}$, and were subsequently separately incubated overnight at $4^{\circ} \mathrm{C}$ with the corresponding primary antibody (1:5,000 dilution). The following primary antibodies were used: Rabbit anti-Toll-like receptor (TLR)-4 (cat. no. bs-1021R; Bioss Biotech, Woburn, MA, USA), rabbit anti-myeloid differentiation primary response gene 88 (MyD88; cat. no. bs-1047R; Bioss Biotech), rabbit anti-c-Jun N-terminal kinase (JNK; cat. no. ab179461; Abcam, Cambridge, UK), rabbit anti-phosphorylated (p)-JNK (cat. no. ab124956; Abcam) and rabbit anti- $\beta$-actin (cat. no. 4967; Cell Signaling Biotechnology, Inc., Danvers, MA, USA). Additionally, the NF- $\mathrm{NB}$ and the p38 MAPK Pathway Sampler kits were used (cat. nos. 9936 and 9913, respectively, Cell Signaling Biotechnology, Inc.). The PVDF membrane was washed with $0.5 \%$ TBS-T solution (Beyotime Institute of Biotechnology, Nantong, China) three times (5 min each). Subsequently, goat anti-rabbit secondary antibody (1:6,000 dilution) conjugated to horseradish peroxidase (cat.no. 3056-1; Epitomics, Inc., Hangzhou, China) was applied to the PVDF membrane, prior to agitation on a rocking bed for $4 \mathrm{~h}$ at room temperature. The membrane was subsequently washed with $0.5 \%$ TBS-T solution three times ( 5 min each). TMB Membrane Peroxidase Substrate (Kirkegaard \& Perry Laboratories, Inc., Gaithersburg, MA, USA) was added onto the membrane. The levels of target proteins were determined using a gel imaging system (ChemiScope 2850, Clinx Science Instruments Co., Ltd., Shanghai, China).

Determination of the growth rate of splenic cells using a 3-(4,5-dimethyl-2-thiazolyl)-2,5-diphenyl-2H-tetrazolium

bromide (MTT) assay. Concanavalin A (ConA), at a final concentration of $5 \mu \mathrm{g} / \mathrm{ml}$, was added to RPMI-1640 culture medium to a $0.2 \mu \mathrm{m}$ filter membrane and stored at $4^{\circ} \mathrm{C}$. MTT (Sigma-Aldrich) was dissolved in PBS to a final concentration of $5 \mathrm{mg} / \mathrm{ml}$ and maintained at $4^{\circ} \mathrm{C}$. The spleen was removed from the mice under the sterile conditions and placed on a flat plate, followed by crushing or cutting. The spleen was subsequently washed with Hank's solution (Sigma-Aldrich) and filtered through four layers of sterile gauze to obtain a suspension of single cells, which were further purified through two successive centrifugation steps at $250 \mathrm{x}$ g for 5 min at $4^{\circ} \mathrm{C}$. The precipitated cells were resuspended in RPMI-1640 culture medium, and the splenic cells obtained were cultured on a 96-well culture plate, with $100 \mu \mathrm{l} /$ well. The final concentration of splenic cells was $1.5 \times 10^{6} / \mathrm{ml}$, to which $100 \mu \mathrm{l}$ ConA solution $(5 \mu \mathrm{g} / \mathrm{ml})$ was added, and the cells were cultured in a $5 \% \mathrm{CO}_{2}$ incubator at $37^{\circ} \mathrm{C}$ for $16 \mathrm{~h}$. An aliquot of $10 \mu \mathrm{l}$ MTT was added into each well prior to the completion of the incubation period. Finally, the cell suspension was centrifuged at $250 \mathrm{x} \mathrm{g}$ for $10 \mathrm{~min}$ at $4^{\circ} \mathrm{C}$, the supernatant was discarded, and $200 \mu 110 \%$ SDS containing $0.04 \mathrm{~mol} / \mathrm{l} \mathrm{HCl}$ was added. The culture plate was agitated on a decolorizing rocking bed for $10 \mathrm{~min}$. The photoabsorption of each well was measured at a wavelength of $490 \mathrm{~nm}$ using a microplate reader (SH 1000; Corona Electric Co., Ltd, Hitachinaka, Japan), the results were recorded and a cell growth curve was constructed, with time on the $\mathrm{x}$-axis and light absorption on the $\mathrm{y}$-axis. The incremental increases in the growth rate of the splenic cells were calculated $24 \mathrm{~h}$ and 7 days following treatment with LPS.

Determination of the humoral immune function. A total of 4 mice were used for this part of the current study, all mice were sacrificed by cervical vertebra dislocation. The mice were immunized with sheep red blood cells (SRBCs; Cell-Bio Biotechnology Co., Ltd., Shanghai, China) and $50 \mathrm{mg}$ of splenic tissues were extracted after 4 days, which were then ground using a 100 mesh copper screen. Subsequently, the extracts were washed twice in Hanks solution and made into a cell suspension with PBS $\left(5 \times 10^{6} / \mathrm{ml}\right)$. For the experimental groups, $1 \mathrm{ml}$ of $0.2 \%$ SRBCs and $1 \mathrm{ml}$ of complement were added to $1 \mathrm{ml}$ of the splenic cell suspension, and the mixture was incubated at $37^{\circ} \mathrm{C}$ for $1 \mathrm{~h}$. Centrifugation was performed at $250 \mathrm{x} \mathrm{g}$ for $5 \mathrm{~min}$ at $4^{\circ} \mathrm{C}$, and the supernatant was obtained. The photoabsorption was measured using a SH-100 microplate reader at $413 \mathrm{~nm}$ (antibody optical density value). In the control group, $1 \mathrm{ml} 0.2 \%$ SRBCs was added to $1 \mathrm{ml}$ splenic cell suspension in a blank tube without complement, and the other procedures were identical with those detailed above.

Assessment of macrophage phagocytosis in mice. Venous blood was extracted from a chicken wing, to which was added physiological saline, and the mixture was centrifuged twice at $250 \mathrm{x} \mathrm{g}$ for $5 \mathrm{~min}$ at $4^{\circ} \mathrm{C}$. Subsequently, an appropriate volume of physiological saline was added, which was determined by the volume of erythrocytes obtained, in order for the concentration of chicken red blood cells (CRBCs; Cell-Bio Biotechnology Co., Ltd.) to be 1\%. At 3 days prior to the experiment, $1 \mathrm{ml}$ soluble amylum (Sigma-Aldrich) was administered to the mice via peritoneal injection every day. At $30 \mathrm{~min}$ prior to the experiment, $1 \mathrm{ml} \mathrm{1 \%}$ CRBCs was administered to the mice via intraperitoneal injection. After 3 days, the mice were sacrificed and $200 \mu \mathrm{l}$ of peritoneal fluid was extracted. A blob of physiological saline solution was dropped onto the slide, to which was added a blob of peritoneal fluid. The liquid was allowed to stand for $10 \mathrm{~min}$ to enable cellular adherence of the ascites to occur, following which the physiological saline solution was discarded, and Wright's staining (Sigma-Aldrich) was performed when the slide had been allowed to dry. A total of 100 mononuclear macrophages were counted on each slide using a CX41 routine microscope (Olympus Corporation, Tokyo, Japan), and the percentage of cells phagocytosing CRBCs were calculated. The percentages of phagocytosing cells were compared across the groups.

Statistical analysis. Data is presented as the mean \pm standard error of the mean, and statistically significant differences 
were assessed by one-way analysis of variance followed by post-hoc analysis. All statistical analyses were processed with Prism version 5 (GraphPad Software, Inc., La Jolla, CA, USA). $\mathrm{P}<0.05$ was considered to indicate a statistically significant difference.

\section{Results}

Changes in the levels of cytokines in the serum. The level of IL-1 $\beta$ in the LPS treatment group was increased at the $2 \mathrm{~h}$ time point following LPS stimulation, with no statistically significant difference following treatment with MSCs, although more marked increases in the levels of IL-1 $\beta$ were observed at the $6 \mathrm{~h}, 24 \mathrm{~h}$ and day 7 time points, with a marked decline following treatment with MSCs. The levels of IL-6 and TNF- $\alpha$ in the LPS treatment group were increased at the $2 \mathrm{~h}$ time point, although without significant difference, compared with the control group. The increase was more clearly discernible at $6 \mathrm{~h}, 24 \mathrm{~h}$ and day 7 time points, with a significant decline following treatment with MSCs. The level of IL-10 in the LPS group exhibited no marked change at the $2 \mathrm{~h}$ time point, and a marginal increase was observed following treatment with MSCs, but without statistical significance, compared with the control and LPS groups. However, a significant increase $(\mathrm{P}<0.05)$ in the levels of IL-10 were observed after $6 \mathrm{~h}, 24 \mathrm{~h}$ and 7 days, with a marked decrease observed following treatment with MSCs. The level of IL-10 in the MSC group declined after $24 \mathrm{~h}$ and 7 days, with a statistically significant difference $(\mathrm{P}<0.05)$, compared with the LPS group. Compared with the control group, no marked changes in cytokines were observed in the MSC group (Fig. 1).

Changes in levels of cytokines in the myocardium. The level of IL-1 $\beta$ in the LPS group was marginally increased at the $2 \mathrm{~h}$ time point following LPS stimulation, however, the increase was not statistically significant, compared with the control group. However, the levels of IL-1 $\beta$ were markedly increased at the $6 \mathrm{~h}, 24 \mathrm{~h}$ and day 7 time points, with a decrease observed following treatment with MSCs, although this was not statistically significant. The levels of IL- 6 and TNF- $\alpha$ in the LPS group exhibited no marked changes at the $2 \mathrm{~h}$ time point, although a marked increase was observed at the $6 \mathrm{~h}, 24 \mathrm{~h}$ and day 7 points, with a significant $(\mathrm{P}<0.05)$ decline observed following MSC treatment. The level of IL-10 in the LPS group did not exhibit a marked change at the $2 \mathrm{~h}$ time point, however, the level was significantly increased at the $6 \mathrm{~h}$ time point $(\mathrm{P}<0.05)$ following MSC treatment. Marked increases in the levels of IL-10 were also observed at the $24 \mathrm{~h}$ and 7 day times points, although the decrease in levels following MSC treatment at these time points were not statistically significant (Fig. 2).

Changes in cardiac function. The level of the ejection fraction (EF) in the LPS group markedly declined at the $2 \mathrm{~h}, 24 \mathrm{~h}$ and 7 day time points following LPS stimulation, which recovered to a differing extent following treatment with the MSCs, which was statistically significant $(\mathrm{P}<0.05)$ for all the time points, with the exception of the $6 \mathrm{~h}$ time point (Fig. 3). On monitoring the changes in the fractional shortening, the results obtained were similar to those obtained for the EF (Fig. 3).
Changes in the protein expression level of myocardial signaling proteins. The protein expression levels of TLR-4 and p65-nuclear factor- $\kappa \mathrm{B}(\mathrm{NF}-\kappa \mathrm{B})$ in the LPS group exhibited no marked changes at the $2 \mathrm{~h}$ time point, however. the observed levels were markedly increased at the $6 \mathrm{~h}, 24 \mathrm{~h}$ and 7 day time points, with lower levels of expression observed following treatment with the MSCs. The protein expression of MyD88 in the LPS group was increased at the $24 \mathrm{~h}$ time point, with a decrease observed following treatment with MSCs. The levels of p-p38 in the LPS group were markedly increased at the $2 \mathrm{~h}$, $6 \mathrm{~h}, 24 \mathrm{~h}$ and 7 day time points, with a decrease observed for all the time points following treatment with MSCs (Fig. 4).

Changes in immunological function. The growth rate of the splenic cells in the LPS group were markedly increased at the $24 \mathrm{~h}$ and 7 day time points, with a marked decease observed following MSC treatment (Fig. 5). No significant differences were identified between the MSC and control group. The humoral immune function in the LPS group was markedly increased at the $24 \mathrm{~h}$ and 7 day time points, with marked decreases observed following treatment with MSCs (Fig. 6). The humoral immune function in the MSCs group declined, compared with the control group. Phagocytosis of the macrophages in the LPS group occurred to a greater extent at the $24 \mathrm{~h}$ and 7 day time points, with marked decreases following treatment with MSCs, although the level of phagocytosis remained higher following MSC treatment, compared with the control group at the $24 \mathrm{~h}$ time point (Fig. 7). Phagocytosis in the MSCs group occurred to a lesser extent than that in the control group after 7 days (Fig. 7).

\section{Discussion}

In the late 1980s, it was hypothesized that inflammatory factors are important in sepsis, and aimed to identify a biomarker to improve diagnostic and prognostic purposes and interfere with inflammatory factors, in order to improve the treatment of sepsis (14). Subsequently, the modes of seizure of sepsis were identified and delineated, with the liberation of several inflammatory factors upon stimulation by LPS at an early stage of disease, and patients with sepsis acquiring immunosuppression at more advanced stages of the disease (15). Therefore, attempts have been made to improve the effectiveness of strategies to treat sepsis clinically, by inhibiting the excessive inflammatory reaction. As LPS is important in sepsis, investigations of the mechanism underlying its action have revealed that LPS activates the inherent (or native) immune system, predominantly through TLR-4 (16), and, following the formation of a complex between TLR-4 and myeloid differentiation factor (2MD-2), LPS activates $\mathrm{NF}-\kappa \mathrm{B}$ via MyD88 to elicit the production of various types of inflammatory factors. The results in the present study revealed that, following stimulation of the mice with LPS, the protein expression levels of TLR-4, MyD88 and NF- $\kappa$ B in the myocardium increased, with corresponding increases in the levels of inflammatory factors in the serum and myocardium. Therefore, the present study hypothesized that an antagonist of TLR-4 may be used to treat sepsis through the interruption of the stimulatory role exerted by LPS on the immune system (2). Although, in early investigations, the antagonist of TLR-4, 

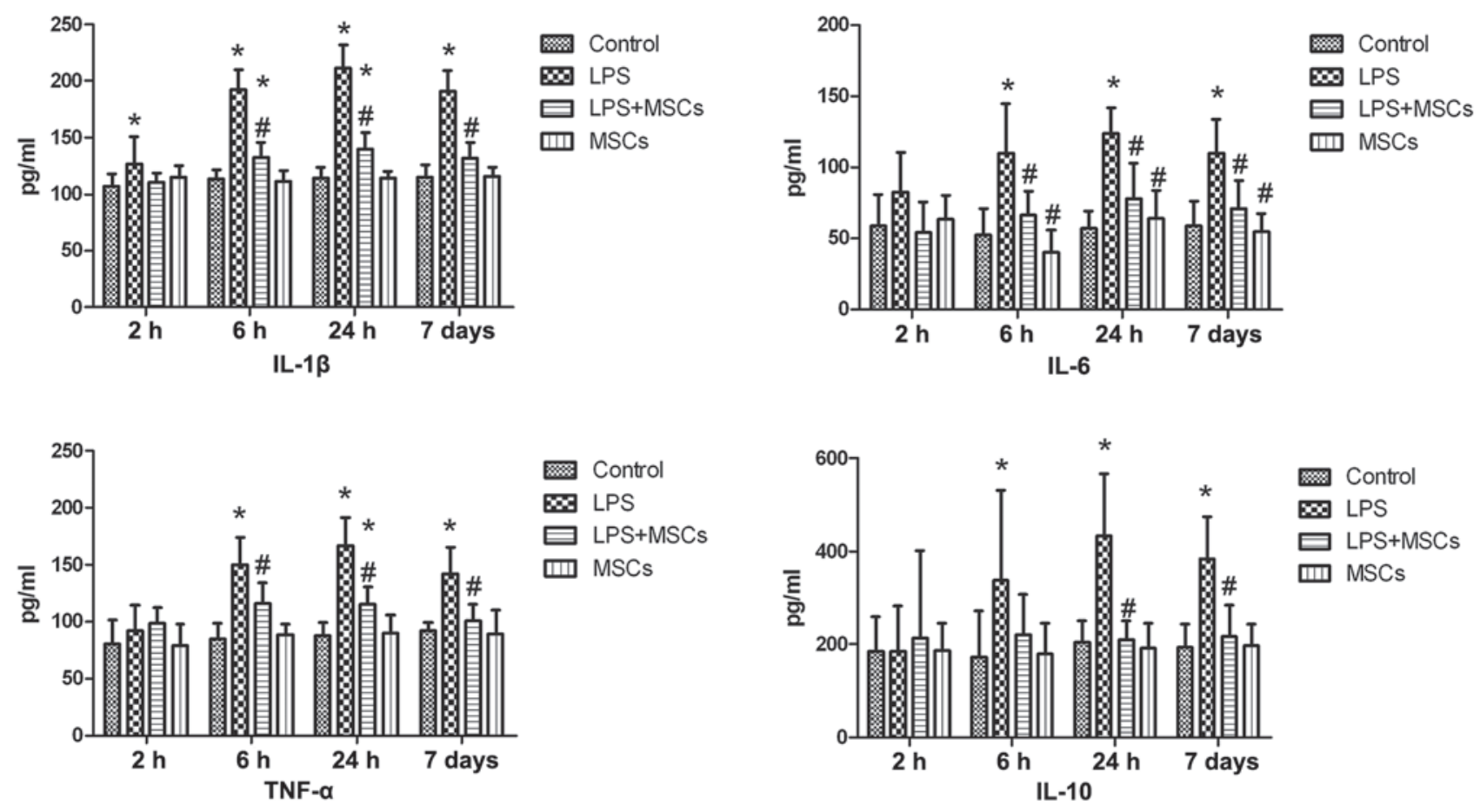

Figure 1. Changes in serum levels of cytokines. The level of IL-1 $\beta$ in the LPS group increased at the $2 \mathrm{~h}$ time point, and more marked increases in the levels of IL-1 $\beta$ were observed at the $6 \mathrm{~h}, 24 \mathrm{~h}$ and 7 day time points, with a marked decline following treatment with MSCs. The levels of IL- 6 and TNF- $\alpha$ in the LPS group were increased at the $6 \mathrm{~h}, 24 \mathrm{~h}$ and 7 day time points, with a marked decline following treatment with MSCs. Compared with the control, the level of IL-10 in the LPS group was not significantly different at the $2 \mathrm{~h}$ time point, but levels were significantly increased at the $6 \mathrm{~h}, 24 \mathrm{~h}$ and $7 \mathrm{day}$ time points, with a significant decline following treatment with MSCs. ${ }^{*} \mathrm{P}<0.05$, compared with the control group; ${ }^{*} \mathrm{P}<0.05$, compared with the LPS group. LPS, lipopolysaccharide; MSC, mesenchymal stem cell; IL, interleukin; TNF- $\alpha$, tumor necrosis factor- $\alpha$.

eritoran, exhibited an apparent tendency to increase the survival rate of patients with sepsis (17), a subsequent large three-stage clinical trial indicated that the mortality rates of patients with sepsis were not lowered as a consequence of treatment with eritoran (6). The possible explanation for this is that the signaling pathway mediated by TLR-4 is not the only route by which LPS acts on the human body. Caspase-11, independently of TLR-4, is also involved in apoptosis induced by LPS $(18,19)$. LPS acts in association with caspase-11, producing an inflammasome following entry to macrophages, and active IL-1 is liberated by the inflammasome under the stimulation of caspase-11 $(20,21)$. In the present study, the level of p-p38 was markedly increased in the LPS group, which was decreased following treatment with MSCs. These results suggested that, as the complex pathogenesis of sepsis remains to be fully elucidated, it is difficult for a treatment regimen aimed at a single factor to exert a marked therapeutical effect on sepsis.

In subsequent studies on sepsis, it has been revealed that the hypothesis suggesting patients with sepsis suffer an excessive inflammatory reaction in the early stages of the disease, and immunosuppression in the advanced stage, was not supported by genomic analyses (22). Thereafter, it has been suggested that the onset of sepsis is accompanied by the activation and inhibition of the immune system (23), with characteristics of abnormal activation predominantly in the early stage, and immunosuppression predominantly in the advanced stage. In addition, the timing and intensity of early immune activation of the body was associated with a range of factors, including the patients' physical status, virulence of pathogenic bacteria and other complicating factors (24). Among patients with refractory sepsis, due to the immunosuppression resulting from a deficiency in the inflammatory factors to activate the adaptive immune system, it is difficult for persistent infections to be controlled (25). The immunosuppression of patients with sepsis is predominantly characterized by the apoptosis of lymphocytes and dendritic cells, decreased expression levels of the cell-surface antigen-presenting complex and human leucocyte antigen-death receptor, and an increase in the expression level of inhibitory immune regulatory molecules, including programmed death 1 and cytotoxic T-lymphocyte-associated antigen 4 . In targeting the immunosuppressive condition, immunostimulatory therapies have been suggested for the treatment of sepsis (26), however, this remains a preliminary stage of investigation, with concerns that they may aggravate the inflammatory reaction and provoke autoimmunity.

There has been increased interest in the ability of MSCs to adjust the function of the immune system extensively, the action of which is twofold and differs from previous treatment regimens. A wealth of evidence has established that MSCs exert a suppressive effect on the innate and adaptive immune systems (27-29). MSCs have been revealed to stimulate the immune system (30). $\gamma$-Interferon stimulates MSCs, generating their antigen-presenting capability, which leads to the stimulation of the adaptive immune system (31). MSCs also stimulate natural B cells and their differentiation and proliferation during transit times, and promote B cells to differentiate into plasma cells following antigenic stimulation (32). As sepsis is associated with an excessive 

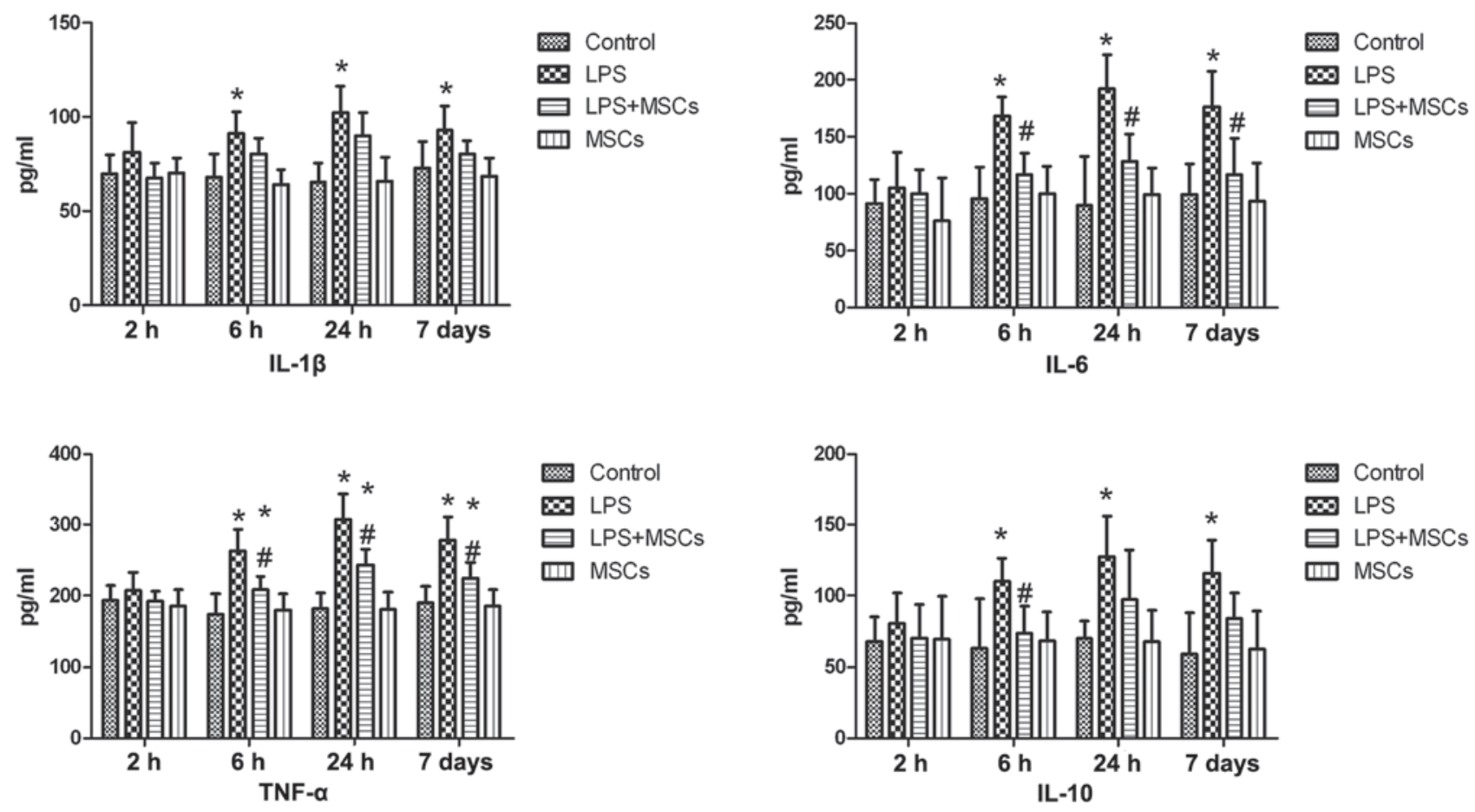

Figure 2. Changes in the levels of cytokines in the myocardium. Compared with the control, the levels of IL-1 $\beta$ increased at the $6 \mathrm{~h}, 24 \mathrm{~h}$ and $7 \mathrm{day}$ time points, with a decline following treatment with MSCs, which was not statistically significant. The levels of IL- 6 and TNF- $\alpha$ in the LPS group exhibited no marked changes at the $2 \mathrm{~h}$ time point, although significant increases in their levels were observed at the $6 \mathrm{~h}, 24 \mathrm{~h}$ and 7 day time points, with a significant decline following MSC treatment. The level of IL-10 in the LPS group exhibited no marked change at the $2 \mathrm{~h}$ time point, although a significant increase was observed at the $6 \mathrm{~h}$ time point, which declined following MSC treatment. A significant increase in the level of IL-10 was also observed at the $24 \mathrm{~h}$ and $7 \mathrm{day}$ time points, although the decline in levels following MSC treatment was not statistically significant. ${ }^{*} \mathrm{P}<0.05$, compared with the control group; ${ }^{*} \mathrm{P}<0.05$, compared with the LPS group. LPS, lipopolysaccharide; MSC, mesenchymal stem cell; IL, interleukin; TNF- $\alpha$, tumor necrosis factor- $\alpha$.

A

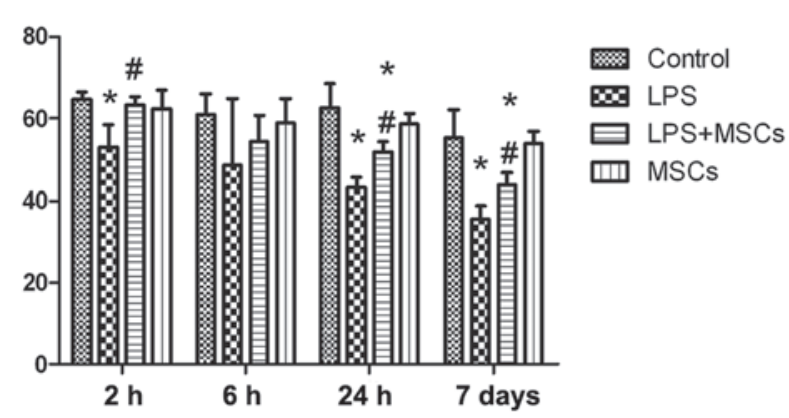

B

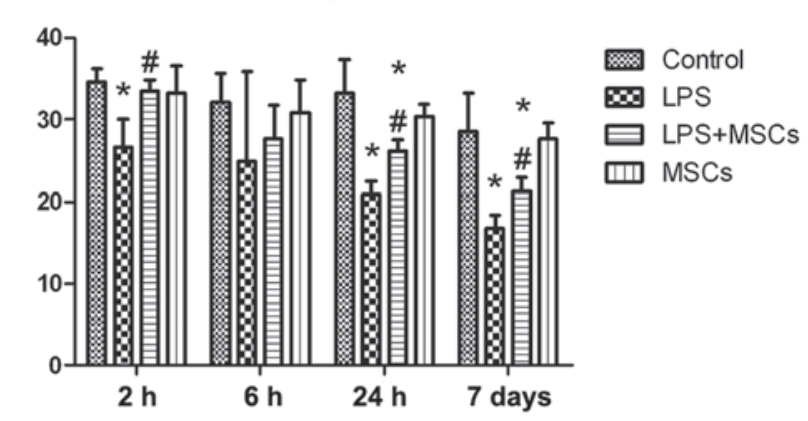

Figure 3. Changes in cardiac function in the different treatment groups. (A) Level of the EF in the LPS group decreased at the $2 \mathrm{~h}$ time point, and also at the $24 \mathrm{~h}$ and 7 day time points, and recovered to a differing extent following MSC treatment. The changes were statistically significant, with the exception of the $6 \mathrm{~h}$ time point. (B) Changes in FS were similar to those for EF. ${ }^{*} \mathrm{P}<0.05$, compared with the control group ${ }^{*} \mathrm{P}<0.05$, compared with the LPS group. EF, ejection fraction; FS, fractional shortening; LPS, lipopolysaccharide; MSC, mesenchymal stem cell.

inflammatory reaction, as well as immunosuppression, the appropriateness of using MSCs in treatment strategies for sepsis remains to be fully elucidated.

In the present study, the inflammatory reaction resulting from LPS stimulation led to a decrease in left cardiac function, similar to sepsis. MSCs have more marked therapeutic effects on cardiac insufficiency in rats with endotoxemia; and they also reduce the expression levels of host of inflammatory factors, including IL-1, TNF- $\alpha$ and IL-6 (7). However, in the present study, the expression of the inflammatory factor, IL-10, following stem cell therapy produced a different experimental result. Németh et al (9) demonstrated that, through stimulating the expression of IL-10, stem cells alleviate the organic damage caused by sepsis. Weil et al (11) demonstrated that, following stem cell therapy, the level of IL-10 in the serum increases. Notably, the present study revealed that, following LPS stimulation, no significant change in the serum level of IL-10 was observed in the LPS group, however, an increase was observed in the MSC group. At $6 \mathrm{~h}, 24 \mathrm{~h}$ and 7 days following treatment, the level of IL-10 in the LPS group increased significantly, and the level of IL-10 declined following treatment with MSCs. The level of IL-10 in the myocardium increased markedly after $6 \mathrm{~h}$, $24 \mathrm{~h}$ and 7 days, and declined following treatment with MSCs. The above-mentioned experimental results are in agreement 

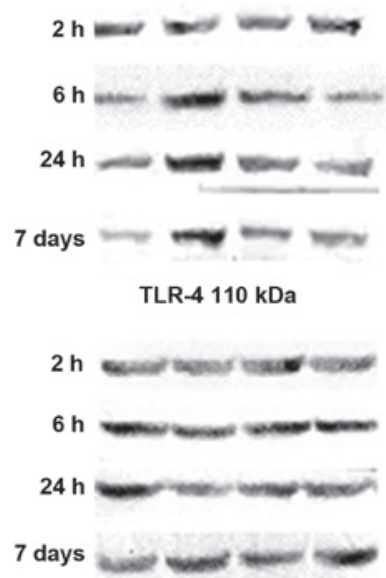

P38 $43 \mathrm{kDa}$

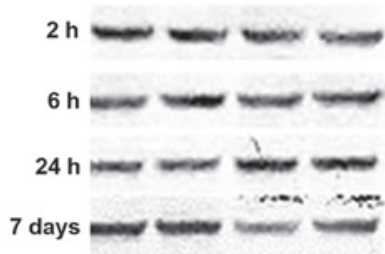

IKB 42 kDa
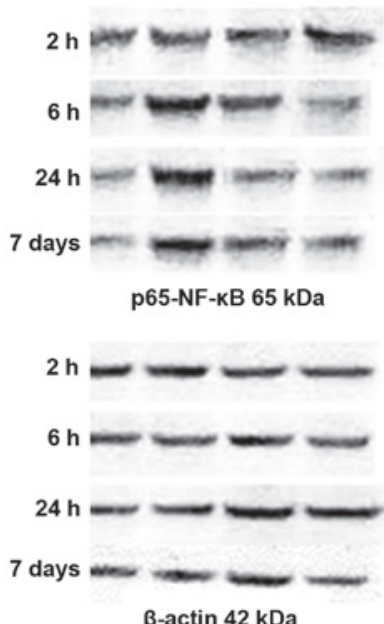

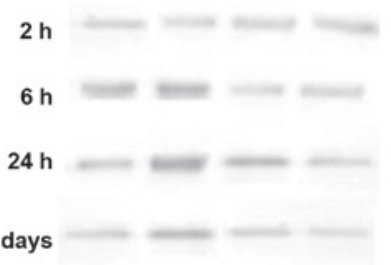

MyD88 33 kDa

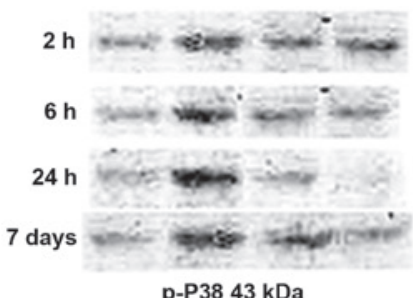

p-P38 $43 \mathrm{kDa}$

$2 \mathrm{~h}$

$6 \mathrm{~h}$

$24 \mathrm{~h}$

7 days

p-IKB 42 kDa

$2 \mathrm{~h}$

$6 \mathrm{~h}$

$24 \mathrm{~h}$

7 days

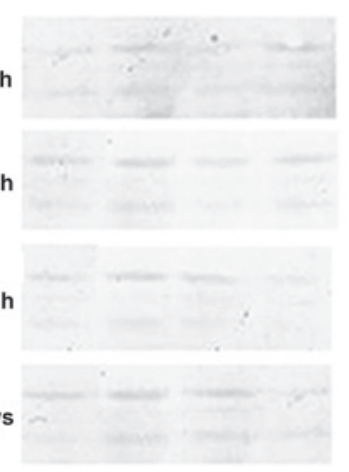

p-JNK $46 \& 54 \mathrm{kDa}$

Figure 4. Changes in the levels of signaling proteins in the myocardium. The protein expression levels of TLR-4 and p65-NF-kB in the LPS group exhibited no marked changes at the $2 \mathrm{~h}$ time point, although the levels were markedly increased at the $6 \mathrm{~h}, 24 \mathrm{~h}$ and 7 day time points, and decreased following treatment with MSCs. The expression of MyD88 in the LPS group increased at the $24 \mathrm{~h}$ time point and declined following MSC treatment. The level of p-p38 in the LPS group was markedly increased at the $2 \mathrm{~h}, 6 \mathrm{~h}, 24 \mathrm{~h}$ and 7 day time points, and decreased following MSC treatment. $\beta$-actin was used as an experimental

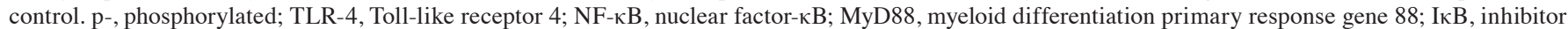
of $\kappa \mathrm{B}$; JNK, c-Jun N-terminal kinase.

A

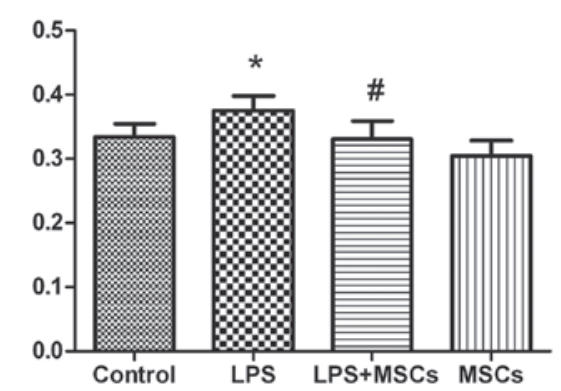

B

\section{7 days}

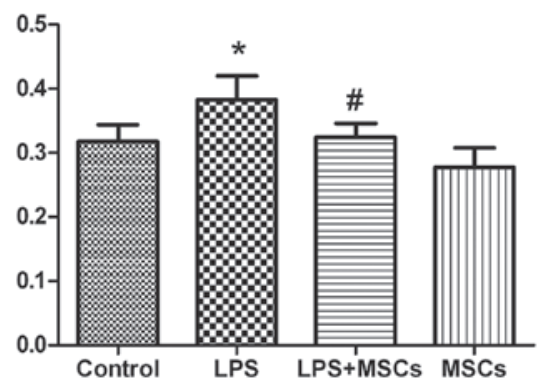

Figure 5. Changes in the splenic cell growth rate. The growth rate of splenic cells in the LPS group was increased markedly at the (A) $24 \mathrm{~h}$ and (B) 7 day time points, with marked decreases observed following MSC treatment. No significant differences were identified between the MSCs alone group and the control group. " $\mathrm{P}<0.05$, compared with the control group; ${ }^{\mathrm{P}} \mathrm{P}<0.05$, compared with the LPS group. LPS, lipopolysaccharide; MSC, mesenchymal stem cell. 
A

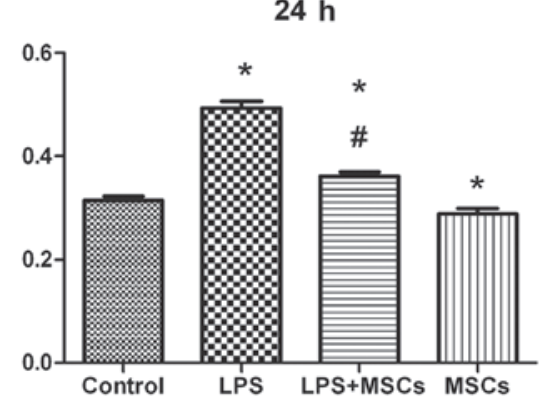

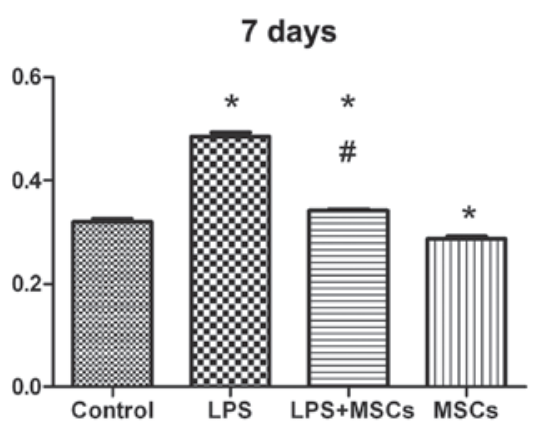

Figure 6. Changes in humoral immune function. Compared with the control, the humoral immune function in the LPS group was significantly increased at the (A) $24 \mathrm{~h}$ and (B) 7 day time points, with significantly decreases observed following MSC treatment. The humoral immune function in the MSCs group decreased, compared with the control group. ${ }^{*} \mathrm{P}<0.05$, compared with the control group; ${ }^{\text {P }}<0.05$, compared with the LPS group. LPS, lipopolysaccharide; MSC, mesenchymal stem cell.

A

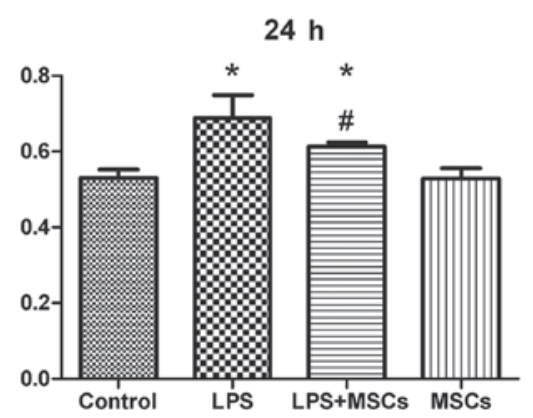

B

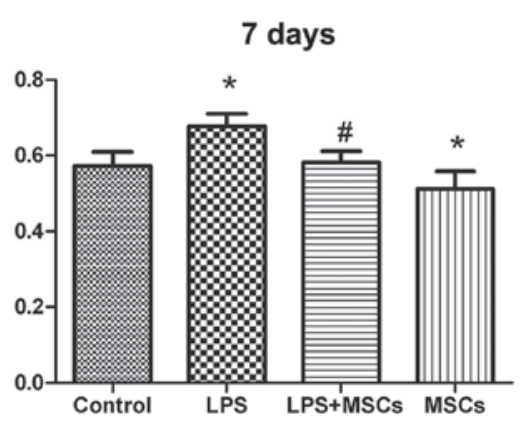

Figure 7. Changes in the levels of phagocytosis in the macrophages. Compared with the control, the extent of phagocytosis of macrophages in the LPS group increased at the (A) $24 \mathrm{~h}$ and (B) 7 day time points, with decreases observed following MSC treatment, although the extent of phagocytosis remained higher at the $24 \mathrm{~h}$ time point, compared with the control group. Levels of phagocytosis in the MSCs group were lower, compared with those in the control group at the 7 day time point. ${ }^{*} \mathrm{P}<0.05$, compared with the control group; ${ }^{\#} \mathrm{P}<0.05$, compared with the LPS group. LPS, lipopolysaccharide; MSC, mesenchymal stem cell.

with the findings of previous studies $(33,34)$. Differences in results among studies may be associated with the different experimental conditions used. Although the expression of IL-10 following treatment with MSCs requires further analysis, the present study hypothesized that MSCs exert a bifunctional role in endotoxemia, by inhibiting inflammatory factors, including IL-1 and IL-6, and inhibiting the compensatory expression of IL-10 following LPS stimulation. This avoids excessive inhibition of immunological function, as excessively inhibiting the inflammatory reaction results in immunosuppression, and a higher ratio of IL-10 to TNF- $\alpha$ is indicative of a poor prognosis in patients with sepsis (35).

In the assessment of the immunological function, the present study demonstrated that the mice in the LPS group manifested an abnormal reinforcement of cellular immunity, humoral immunity and phagocytosis of macrophages during the first week, which declined following treatment with MSCs. The humoral immune function in the MSC group was lower, compared with that in the control group. By contrast, no significant differences were identified in humoral or cellular immune function among the LPS, MSC or control groups, which indicated that the presence of MSCs in the mice with endotoxemia did not markedly suppress their adaptive immune response. In the present study, during the monitoring of the mice for 1 week, the immunological function remained in the stage of reinforcement, although immunosuppression did not manifest itself during sepsis, which may have been associated with the experimental approach used. Therefore, further investigations are required to examine the effects of MSCs on mice with sepsis predominantly accompanied by immunosuppression.

In conclusion, the present study indicated that MSCs exert regulatory roles in the immune system in several diverse ways, by inhibiting the excessive inflammatory reaction and reinforcing the immunological function, and by avoiding the abnormal increase in anti-inflammatory IL-10. Using MSCs to treat sepsis may circumvent the difficulties associated with therapies are aimed at single cytokines or other molecules. MSCs are readily obtained and easy to culture in vitro, with rapid and simple amplification. Previous studies have also shown that MSCs may exert antibiotic action by excreting antimicrobial peptide LL-37, thereby stimulating neutrophil granulocytes $(36,37)$. Another advantage is that their immunogenicity is low, which makes it possible to treat sepsis using allogeneic stem cells. Taken together, the results of the present study confirmed that the therapeutic effects and underlying mechanism of MSCs in the treatment of sepsis require further investigation, in order to develop novel approaches for the treatment for sepsis.

\section{References}

1. Levy MM, Dellinger RP and Townsend SR, Linde-Zwirble WT, Marshall JC, Bion J, Schorr C, Artigas A, Ramsay G, Beale R, et al: The Surviving Sepsis Campaign: Results of an international guideline-based performance improvement program targeting severe sepsis. Intensive Care Med 36: 222-231, 2010.

2. Ianaro A, Tersigni M and D'Acquisto F: New insight in LPS antagonist. Mini Rev Med Chem 9: 306-317, 2009. 
3. Gioannini TL and Weiss JP: Regulation of interactions of Gram-negative bacterial endotoxins with mammalian cells. Immunol Res 39: 249-260, 2007.

4. Marshall JC, Charbonney E and Gonzalez PD: The immune system in critical illness. Clin Chest Med 29: 605-616, vii, 2008

5. Torgersen C, Moser P, Luckner G, Mayr V, Jochberger S, Hasibeder WR and Dünser MW: Macroscopic postmortem findings in 235 surgical intensive care patients with sepsis. Anesth Analg 108: 1841-1847, 2009.

6. Opal SM, Laterre PF, Francois B, LaRosa SP, Angus DC, Mira JP, Wittebole X, Dugernier T, Perrotin D, Tidswell M, et al ACCESS Study Group: Effect of eritoran, an antagonist of MD2-TLR4, on mortality in patients with severe sepsis: The ACCESS randomized trial. JAMA 309: 1154-1162, 2013.

7. Gonzalez-Rey E, Anderson P, González MA, Rico L, Büscher D and Delgado M: Human adult stem cells derived from adipose tissue protect against experimental colitis and sepsis. Gut 58: 929-939, 2009.

8. Lee JW, Fang X, Gupta N, Serikov V and Matthay MA: Allogeneic human mesenchymal stem cells for treatment of E. coli endotoxin-induced acute lung injury in the ex vivo perfused human lung. Proc Natl Acad Sci USA 106: 16357-16362, 2009.

9. Németh K, Leelahavanichkul A, Yuen PS, Mayer B, Parmelee A, Doi K, Robey PG, Leelahavanichkul K, Koller BH, Brown JM, et al: Bone marrow stromal cells attenuate sepsis via prostaglandin $\mathrm{E}(2)$-dependent reprogramming of host macrophages to increase their interleukin-10 production. Nat Med 15: 42-49, 2009.

10. Weil BR, Manukyan MC, Herrmann JL, Wang Y, Abarbanell AM, Poynter JA and Meldrum DR: Mesenchymal stem cells attenuate myocardial functional depression and reduce systemic and myocardial inflammation during endotoxemia. Surgery 148 : 444-452, 2010

11. Weil BR, Herrmann JL, Abarbanell AM, Manukyan MC, Poynter JA and Meldrum DR: Intravenous infusion of mesenchymal stem cells is associated with improved myocardia function during endotoxemia. Shock 36: 235-241, 2011.

12. Opal SM, Scannon PJ, Vincent JL, White M, Carroll SF, Palardy JE, Parejo NA, Pribble JP and Lemke JH: Relationship between plasma levels of lipopolysaccharide (LPS) and LPS-binding protein in patients with severe sepsis and septic shock. J Infect Dis 180: 1584-1589, 1999.

13. Marshall JC, Foster D, Vincent JL, Cook DJ, Cohen J, Dellinger RP, Opal S, Abraham E, Brett SJ, Smith T, et al: MEDIC study: Diagnostic and prognostic implications of endotoxemia in critical illness: Results of the MEDIC study. J Infect Dis 190 527-534, 2004

14. Bone RC, Balk RA, Cerra FB, Dellinger RP, Fein AM, Knaus WA, Schein RM and Sibbald WJ: The ACCP/SCCM Consensus Conference Committee. American College of Chest Physicians/Society of Critical Care Medicine: Definitions for sepsis and organ failure and guidelines for the use of innovative therapies in sepsis. Chest 101:1644-1655, 1992.

15. Hotchkiss RS and Karl IE: The pathophysiology and treatment of sepsis. N Engl J Med 348: 138-150, 2003.

16. Medzhitov R: Approaching the asymptote: 20 years later Immunity 30: 766-775, 2009 .

17. Tidswell M, Tillis W, Larosa SP, Lynn M, Wittek AE, Kao R, Wheeler J, Gogate J and Opal SM; Eritoran Sepsis Study Group: Phase 2 trial of eritoran tetrasodium (E5564), a Toll-like receptor 4 antagonist, in patients with severe sepsis. Crit Care Med 38: 72-83, 2010.

18. Hagar JA, Powell DA, Aachoui Y, Ernst RK and Miao EA Cytoplasmic LPS activates caspase-11: Implications in TLR4-independent endotoxic shock. Science 341: 1250-1253, 2013.
19. Kayagaki N, Wong MT, Stowe IB, Ramani SR, Gonzalez LC, Akashi-Takamura S, Miyake K, Zhang J, Lee WP, Muszyński A, et al: Noncanonical inflammasome activation by intracellular LPS independent of TLR4. Science 341: 1246-1249, 2013.

20. Ng TM and Monack DM: Revisiting caspase-11 function in host defense. Cell Host Microbe 14: 9-14, 2013.

21. Lamkanfi M and Dixit VM: Inflammasomes: Guardians of cytosolic sanctity. Immunol Rev 227: 95-105, 2009.

22. Tang BM, Huang SJ and McLean AS: Genome-wide transcription profiling of human sepsis: A systematic review. Crit Care 14: R237, 2010

23. Monneret G, Venet F, Pachot A and Lepape A: Monitoring immune dysfunctions in the septic patient: A new skin for the old ceremony. Mol Med 14: 64-78, 2008.

24. Skrupky LP, Kerby PW and Hotchkiss RS: Advances in the management of sepsis and the understanding of key immunologic defects. Anesthesiology 115: 1349-1362, 2011.

25. Salomao R, Brunialti MK, Rapozo MM, Baggio-Zappia GL, Galanos C and Freudenberg M: Bacterial sensing, cell signaling, and modulation of the immune response during sepsis. Shock 38: 227-242, 2012.

26. Hotchkiss RS and Opal S: Immunotherapy for sepsis - a new approach against an ancient foe. N Engl J Med 363: 87-89, 2010.

27. Beyth S, Borovsky Z, Mevorach D, Liebergall M, Gazit Z, Aslan H, Galun E and Rachmilewitz J: Human mesenchymal stem cells alter antigen-presenting cell maturation and induce T-cell unresponsiveness. Blood 105: 2214-2219, 2005.

28. Aggarwal S and Pittenger MF: Human mesenchymal stem cells modulate allogeneic immune cell responses. Blood 105: 1815-1822, 2005.

29. Ramasamy R, Fazekasova H, Lam EW, Soeiro I, Lombardi G and Dazzi F: Mesenchymal stem cells inhibit dendritic cell differentiation and function by preventing entry into the cell cycle. Transplantation 83: 71-76, 2007.

30. Stagg J: Immune regulation by mesenchymal stem cells: Two sides to the coin. Tissue Antigens 69: 1-9, 2007.

31. Chan JL, Tang KC and Patel AP, Bonilla LM, Pierobon N, Ponzio NM and Rameshwar P: Antigen-presenting property of mesenchymal stem cells occurs during a narrow window at low levels of interferon-gamma. Blood 107: 4817-4824, 2006.

32. Traggiai E, Volpi S and Schena F, Gattorno M, Ferlito F, Moretta L and Martini A: Bone marrow-derived mesenchymal stem cells induce both polyclonal expansion and differentiation of B cells isolated from healthy donors and systemic lupus erythematosus patients. Stem Cells 26: 562-569, 2008.

33. Shin S, Kim Y, Jeong S, Hong S, Kim I, Lee W and Choi S: The therapeutic effect of human adult stem cells derived from adipose tissue in endotoxemic rat model. Int J Med Sci 10: 8-18, 2013.

34. Mei SH, Haitsma JJ, Dos Santos CC, Deng Y, Lai PF, Slutsky AS, Liles WC and Stewart DJ: Mesenchymal stem cells reduce inflammation while enhancing bacterial clearance and improving survival in sepsis. Am J Respir Crit Care Med 182: 1047-1057, 2010.

35. van Dissel JT, van Langevelde P, Westendorp RG, Kwappenberg K and Frölich M: Anti-inflammatory cytokine profile and mortality in febrile patients. Lancet 351: 950-953, 1998

36. Krasnodembskaya A, Song Y and Fang X, Gupta N, Serikov V, Lee JW and Matthay MA: Antibacterial effect of human mesenchymal stem cells is mediated in part from secretion of the antimicrobial peptide LL-37. Stem Cells 28: 2229-2238, 2010.

37. Hall SR, Tsoyi K, Ith B, Padera RF Jr, Lederer JA, Wang Z, Liu X and Perrella MA: Mesenchymal stromal cells improve survival during sepsis in the absence of heme oxygenase-1: the importance of neutrophils. Stem Cells 31: 397-407, 2013. 